\title{
Does informed consent influence therapeutic outcome? A clinical trial of the hypnotic activity of placebo in patients admitted to hospital
}

\author{
R DAHAN, C CAULIN, L FIGEA, J A KANIS, F CAULIN, J M SEGRESTAA
}

\begin{abstract}
To examine whether written informed consent might influence the results of clinical trials the effect of placebo when given with or without informed consent to patients suffering from insomnia was studied. The study was a single blind observer blinded trial, and patients were paired according to sex, age, and hospital environment. Randomisation assigned the first patient of each pair to the control group (without informed consent) or the group to give informed consent. Of the 56 patients, 26 refused to give informed consent, and the age and sex distribution of these differed significantly $(p<0.02)$ from the 30 pairs of patients ultimately enrolled into the study. In this "biased" sample, the hypnotic activity of placebo was significantly higher in the control group $(\mathbf{p}<0 \cdot 05)$.

It is concluded that the informed consent procedure biases the results of clinical trials and might affect their general applicability.
\end{abstract}

\section{Introduction}

Requirement of informed consent before patients enter a randomised clinical trial is an ethical obligation ${ }^{12}$; however, there are several difficulties and disadvantages inherent in obtaining informed consent. ${ }^{3}$ Of particular concern is the fact that the outcome of a clinical trial may be altered because a biased population is selected by the procedure for obtaining consent.

In order to examine whether informed consent might lead to biased sampling of the population and influence response to treatment we studied the effect of placebo when given with or without informed consent.

\section{Patients and methods}

This study was designed as a randomised single blind, observer blinded trial. Over five months 189 patients of both sexes who had been admitted to hospital for more than two days and were suffering from insomnia (difficulty in falling asleep, difficulty in staying asleep, or early morning wakefulness) were considered for inclusion into the study. Of these, 103 patients were excluded before randomisation for the following reasons: psychiatric disorders $(n=11)$; use of drugs that commonly cause insomnia or induce sleep $(n=28)$; insomnia due to non-specific medical symptoms such as pain, dysuria, fever, etc $(n=25)$ or to nursing procedures $(n=12)$; sensorial or cognitive dysfunction $(n=20)$; and other miscellaneous reasons $(n=7)$.

\footnotetext{
Clinique Thérapeutique, Hôpital Lariboisiere, 75475 Paris Cedex 10

R DAHAN, MD, consultant physician

C CAULIN, MD, professor of therapeutics

L FIGEA, MD, consultant physician

F CAULIN, MD, consultant physician

J M SEGRESTAA, MD, professor of therapeutics

Department of Human Metabolism and Clinical Biochemistry, University of Sheffield, Sheffield S10 2RX

J A KANIS, MD, consultant physician

Correspondence to: Dr Dahan.
}

The remaining 86 patients were first paired according to sex, age $(<60$, $\geqslant 60$ years old), and hospital environment (single or double room). The first patient in each pair was then assigned randomly to the control group (without informed consent and thus without information on their participation in a clinical trial) or to the group that gave written informed consent. If a patient refused to give informed consent the next patient with the same characteristics was asked to give informed consent to participate in the trial. The document given to obtain informed consent suggested that the patient was being asked to participate in a study evaluating the potential therapeutic value of a drug for insomnia. It explained the use of randomisation and of a placebo control group and described possible side effects of the drug (the side effects of benzodiazepines). Twenty six patients declined to give informed consent.

After definitive inclusion into the trial, two days after admission to hospital, all of the remaining 60 patients received one placebo tablet one to two hours before going to bed. The next morning each patient evaluated sleep subjectively on a four point scale and reported any side effects to an independent observer. Data were analysed using Wilcoxon's signed rank test and McNemar's test for paired observations.

\section{Results}

Twenty six $(46.4 \%)$ of the 56 patients assigned by randomisation to the consent group refused to give their consent because of reluctance to participate in the study $(n=12)$ or fear of side effects $(n=10)$ or because they wished to take a well known drug $(n=4)$. Women aged over 60 were significantly less disposed than others to give informed consent $\left(\chi^{2}=5 \cdot 58\right.$; $\mathrm{p}<0.02)$. Because of this specific effect, the population suffering from insomnia and the patients enrolled into the study differed in the distribution of both age and sex (table I).

When the results of treatment in 30 pairs of patients were analysed (table II) there was a significant difference between the two groups of patients, with better hypnotic activity in the control group than among those who had given informed consent $(p<0.05$, Wilcoxon's signed rank test). Four side effects were spontaneously reported in the consent group (sweating, headache, hypotonia, anxiety) and none in the control group $(p=0 \cdot 12$, McNemar's test).

TABLE I-Age and sex distribution of 56 patients who gave or refused to give informed consent

\begin{tabular}{lccccccc}
\hline & \multicolumn{2}{c}{ Women } & & \multicolumn{3}{c}{ Men } & \\
\cline { 2 - 3 } & $\geqslant 60$ & $<60$ & & $\geqslant 60$ & $<60$ & Total \\
\hline Consent given & 9 & 7 & & 9 & 5 & 30 \\
Consent refused & 18 & 1 & & 3 & 4 & 26 \\
\hline \multicolumn{1}{c}{ Total } & 27 & 8 & & 12 & 9 & 56
\end{tabular}

For women $\geqslant 60 v$ other patients $\gamma^{2}=5 \cdot 58, \mathrm{df}=1 ; \mathrm{p}<0 \cdot 02$.

TABLE II-Matched pairs analysis of patients' subjective evaluation of sleep

\begin{tabular}{lccccc}
\hline & \multicolumn{5}{c}{ Informed consent group } \\
\cline { 2 - 6 } Control group & Excellent & Good & Mediocre & Very bad & Total \\
\hline Excellent & 0 & 1 & 3 & 2 & 6 \\
Good & 2 & 0 & 2 & 3 & 7 \\
Mediocre & 1 & 0 & 4 & 6 & 11 \\
Very bad & 0 & 1 & 4 & 1 & 6 \\
Total & 3 & 2 & 13 & 12 & 30 \\
\hline
\end{tabular}

Wilcoxon's signed rank test, $\mathrm{p}<0.05$. 


\section{Discussion}

Obtaining informed consent had at least three disadvantages in our study. It increased the duration of the trial, it modified the characteristics of the population included in the clinical trial, and it affected the therapeutic response obtained with the drug. Additional disadvantages that we did not evaluate include the anxiety induced by the experiment and guilt when refusing to give consent.

The bias introduced by informed consent can be negative as in our trial, in which it spuriously decreased the apparent efficacy of placebo, although opposite effects might be observed in other trials. Nevertheless, the important finding is that this effect may occur and should be taken into account when the outcomes of clinical trials are assessed.

We are aware of several limitations in our study, because we studied insomnia in patients admitted to hospital and evaluated placebo after only one dose. Inclusion of patients admitted to hospital is not ideal because of the many possible causes of insomnia in this population. The exclusion criteria, however, permitted us to study a fairly homogeneous group of patients, whose insomnia was not obviously due to illness, hospital environment, or drugs. ${ }^{+}$We tried, moreover, to limit the anxiety caused by the trial by not including patients in the study until their second day in hospital.

We chose to study insomnia for ethical reasons; it would have been impossible to conduct such a trial among patients with a more serious condition or with a longer follow up period. As the hypnotic activity of a drug can reasonably be assessed after a single dose, insomnia was considered an appropriate model for our purpose. This model obviously did not enable us to ascertain the value of informed consent for long term treatment, when the educational value of printed information can improve compliance and may have a therapeutic benefit. ${ }^{6}$ The value of written informed consent, however, is often dubious because the information provided may be scanty, misunderstood, or forgotten. ${ }^{7 \cdot 10}$

We did not compare the activity of a hypnotic drug with placebo in our two groups of patients. Had we done so and found a similar result in favour of the active compound it could be argued that the effect introduced by informed consent would not alter the conclu- 3 sion that the drug was effective. In clinical practice, however, $\stackrel{\mathbb{Q}}{\Omega}$ doctors are also concerned about the degree of efficacy which canc clearly be modified by informed consent.

The general applicability of the results of trials to the population who will ultimately be treated by the drug is a problem that increasingly required attention. ${ }^{11}$ This problem arises because ${ }^{\infty}$ clinical trials use very narrow eligibility criteria, highly competent 2 investigators, and special dosages or combinations of treatments. Our work shows that this problem can be complicated by a "consent $\overrightarrow{\vec{\rho}}$ effect." One way to minimise this would be to standardise theinformation given to a patient in normal clinical practice and in $\frac{5}{5}$ randomised clinical trials. Whether this would be a service or $\overline{\bar{s}}$ disservice to medicine is arguable but merits consideration in those $\vec{\nabla}$ specialties concerned with clinical trials.

\section{References}

Cancer research campaign workıng party in breast conservation. Informed consent: ethical, legal and medical implications for doctors and patients who participate in randomised clinical trials. Br Med J 1983;286:1117-21.

2 Schafer A. The ethics of the randomized clinical trial. N Engl I Med 1982;307:719-24.

3 Brewin TB. Consent to randomized treatment. Lancet 1982;ii-919-21.

(c)

Oswald I Sleep studies in clinical pharmacology. Br f Clin Pharmal 1980:10:317-26. f

Meisel A, Roth LH. What we do and do not know about informed consent. fAMA 1981;246: ठூ 2473-7.

8 Massar M, W' eintraub M. Uninformed consent and the wealthy volunteer: an analysis of patient 0 volunteers in a clinical trial of a new anti-inflammatory drug. Clin Pharmacol Ther 1976;20: 379-86.

Riecken HW, Ravich R. Informed consent to biomedical research in Veterans Administration hospitals. FAMA 1982;248:344-8.

10 Stanley B, Guido J, Stanley M, Shortell D. The elderly patient and informed consent, empirical $\frac{C}{\infty}$ 11 Brown BW. The randomized clinical trial. Statistics in Medicine 1984;3:307-11.

(Accepted 3 fune 1986

\section{SHORT REPORTS}

\section{Increased risk of sudden infant death syndrome in older infants at weekends}

Sudden infant death syndrome is the commonest cause of postperinatal mortality in infancy. Descriptions of its epidemiological features are surprisingly consistent for a condition diagnosed by exclusion, the causes of which remain controversial. Variation in the occurrence of sudden infant death syndrome according to the day of the week is disputed, ${ }^{\prime}$ as is the existence of two subgroups distinguished epidemiologically by different ages at death (under 3 months and over 3 months). ${ }^{2}$ Accordingly as part of a larger study of seasonal effects on sudden infant death syndrome we have analysed the occurrence of 6226 cases by day of the week and age at death.

\section{Methods and results}

A total of 6226 deaths in which the underlying cause was given as sudden infant death syndrome (795 ICD8, 798.0 ICD9) or the phrase "sudden infant death" or an equivalent appeared anywhere on the death certificate were included in the analysis. ${ }^{3}$ Data were obtained from the Office of Population Censuses and Surveys and covered the period Monday 1 January 1979 to Saturday 31 December 1983. The day of the week on which the death occurred and the age of the infant were noted in each case.

The table shows the mean numbers of deaths by day of the week and age, together with the ratio of the daily to overall mean. For each day of the week the number of observed deaths was compared with the number expected under the null hypothesis of no variation throughout the week using a $\chi^{2}$ statistic with 6 degrees of freedom. For deaths at all ages there was a significant excess at weekends, due largely to the deaths of older children, which increased steadily from Monday to Sunday. Deaths of younger children showed no association with day of the week.
Daily mean number of deaths with sudden infant death syndrome mentioned on certificate by age, England and Wales 1979-83. Values in parentheses are ratios of observed to expected deaths

\begin{tabular}{|c|c|c|c|c|}
\hline & $\begin{array}{l}\text { Deaths under } \\
3 \text { months }\end{array}$ & $\begin{array}{c}\text { Deaths at } \\
3 \text { months to } 1 \text { year }\end{array}$ & $\begin{array}{l}\text { All deaths } \\
\text { under I year }\end{array}$ & $\begin{array}{c}95 \% \\
\text { Confidence } \\
\text { interval* }\end{array}$ \\
\hline Monday & $1.56(0.99)$ & $1.69(0.92)$ & $3.25(0.95)$ & $(0.89$ to 1.01$)$ \\
\hline Tuesday & $1.56(0.99)$ & $1.72(0.94)$ & $3.28(0.96)$ & $(0.90$ to 1.02$)$ \\
\hline Wednesday & $1.51(0.96)$ & $1.75(0.95)$ & $3.26(0.96)$ & $(0.90$ to 1.02$)$ \\
\hline Thursday & $1.64(1.04)$ & $1.83(1.00)$ & $3.47(1.02)$ & $(0.95$ to 1.09$)$ \\
\hline Friday & $1.44(0.92)$ & $1.87(1.02)$ & $3.31(0.97)$ & $(0.91$ to 1.03$)$ \\
\hline Saturday & $1.70(1.08)$ & $2.00(1.09)$ & $3.70(1.09)$ & $(1.07$ to 1.16$)$ \\
\hline Sunday & $1.59(1.01)$ & $2.02(1.09)$ & $3.61(1.06)$ & $(0.99$ to $1 \cdot 13)$ \\
\hline \multirow[t]{3}{*}{ All days } & $1.57(1.00)$ & $1 \cdot 84(1.00)$ & $3.41(1.00)$ & \\
\hline & $x^{2}=7 \cdot 10$ & $x^{2}=14 \cdot 8$ & $x=15 \cdot 5$ & \\
\hline & $\begin{array}{c}\mathrm{df}=6 \\
\mathrm{p}=0 \cdot 3\end{array}$ & $\begin{array}{c}\mathrm{df}=6 \\
\mathrm{p}=0.025\end{array}$ & $\begin{array}{c}d f=6 \\
p=0.017\end{array}$ & \\
\hline
\end{tabular}

There were 2867 deaths under the age of 3 months and 3359 between 3 months and 1 year; these occurred over 1826 davs.

* $95 \%$ confidence interal for the ratio of all observed deaths under 1 year to expected deaths under 1 year.

\section{Comment}

In England and Wales most cases of sudden infant death syndrome are응 certified by the coroner, whose prime responsibility is to investigate and exclude violent or unnatural causes of death. Because of the difficulty in identifying true cases of sudden infant death syndrome by means of routine? data, the Office of Population Censuses and Surveys considers "mentions" 